\title{
Number Sequencing and Architecture
}

\author{
Nick Huo Han Huang
}

Pingguoyuan D-9B, Renmin Road, Longhua District, Shenzhen, Guangdong, China, 518129

Received: November 26, 2017 / Accepted: December 21, 2017 / Published: May 25, 2018.

\begin{abstract}
In Chinese, Mathematics is “数学”, i.e. Numbers (数) Knowledge (学). Human identifies us ourselves from the whole one of the Universe by means of numbers, and numbers are equal object status identities, and numbers counting means repetition, i.e. the process or time dimension. Given a series of n numbers, $a_{1}, a_{2}, \ldots, a_{n}, n \in N$, i.e. the $n$ objects of status, and a general formula a(i) for ordering all of the number terms by $\mathrm{i}$ ( $\mathrm{i}=1$ to $\mathrm{n}$ ) can be generated, which shows a process of counting, and from sequencing to progression, some properties are extracted.
\end{abstract}

Key words: Natural Numbers, Integers, Number Sequence, Combinations.

\section{Finite Number Sequence}

Giving $\mathrm{n} \in \mathrm{N}$, and the numbers $\mathrm{a}_{1}, \mathrm{a}_{2}, \ldots, \mathrm{a}_{\mathrm{n}}$, form a Finite Number Sequence, $\mathrm{n}$ is the order of the sequence. Without loss of generality, all $\mathrm{a}_{\mathrm{i}}(\mathrm{i}=1$ to $\mathrm{n})$ are integers. Considering an integer discrete function $\mathrm{a}(\mathrm{i})=\mathrm{a}_{\mathrm{i}}$, then the below formula can be constructed.

$$
\begin{gathered}
\mathrm{a}(\mathrm{i})=\mathrm{a}_{1}+(\mathrm{i}-1)\left\{\mathrm{a}_{2}-\mathrm{a}_{1}+(\mathrm{i}-2)\left[\left(\mathrm{a}_{3}-2 \mathrm{a}_{2}+\mathrm{a}_{1}\right) / 2+(\mathrm{i}-3)\left(\left(\mathrm{a}_{4}\right.\right.\right.\right. \\
\left.-3 \mathrm{a}_{3}+3 \mathrm{a}_{2}-\mathrm{a}_{1}\right) / 6+\ldots+ \\
\left(\mathrm{a}_{\mathrm{i}}-(\mathrm{i}-1) \mathrm{a}_{\mathrm{i}-1}+\ldots+(-1)^{\mathrm{i}-\mathrm{k}(}\left(\begin{array}{c}
\mathrm{i}-1 \\
\mathrm{i}-\mathrm{k}
\end{array}\right) \mathrm{a}_{\mathrm{k}}+\ldots+(-1)^{\mathrm{i}-2}(\mathrm{i}-1) \mathrm{a}_{2}+\right. \\
\left.\left.\left.\left.(-1)^{\mathrm{i}-1} \mathrm{a}_{1}\right) /(\mathrm{i}-1) !+(\mathrm{i}-\mathrm{i})(X)\right)\right]\right\}
\end{gathered}
$$

The last term in italics, $(i-i)(X)$, is always zero, though. And

$$
\begin{gathered}
\mathrm{a}(\mathrm{i})=\mathrm{a}_{1}+(\mathrm{i}-1)\left\{\mathrm{a}_{2}-\mathrm{a}_{1}+(\mathrm{i}-2)\left[\left(\mathrm{a}_{3}-2 \mathrm{a}_{2}+\mathrm{a}_{1}\right) / 2+(\mathrm{i}-3)\left(\left(\mathrm{a}_{4}\right.\right.\right.\right. \\
\left.-3 \mathrm{a}_{3}+3 \mathrm{a}_{2}-\mathrm{a}_{1}\right) / 6+\ldots+ \\
\left.\left.\left.\left(\mathrm{a}_{\mathrm{i}}-(\mathrm{i}-1) \mathrm{a}_{\mathrm{i}-1}+\ldots+(-1)^{\mathrm{i}-2}(\mathrm{i}-1) \mathrm{a}_{2}+(-1)^{\mathrm{i}-1} \mathrm{a}_{1}\right) /(\mathrm{i}-1) !\right)\right]\right\} \\
=\mathrm{a}_{1}+(\mathrm{i}-1)\left(\mathrm{a}_{2}-\mathrm{a}_{1}\right)+(\mathrm{i}-1)(\mathrm{i}-2)\left(\mathrm{a}_{3}-2 \mathrm{a}_{2}+\mathrm{a}_{1}\right) / 2+(\mathrm{i}-1)(\mathrm{i}- \\
2)(\mathrm{i}-3)\left(\mathrm{a}_{4}-3 \mathrm{a}_{3}+3 \mathrm{a}_{2}-\mathrm{a}_{1}\right) / 6+\ldots+ \\
(\mathrm{i}-1)(\mathrm{i}-2) \ldots(\mathrm{i}-\mathrm{k}+1)\left[\mathrm{a}_{\mathrm{k}}-(\mathrm{k}-1) \mathrm{a}_{\mathrm{k}-1}+\ldots+(-1)^{\mathrm{k}-\mathrm{j}}\left(\begin{array}{c}
k-1 \\
k-j
\end{array}\right)\right. \\
\left.\mathrm{a}_{\mathrm{j}}+\ldots+(-1)^{\mathrm{k}-2}(\mathrm{k}-1) \mathrm{a}_{2}+(-1)^{\mathrm{k}-1} \mathrm{a}_{1}\right] /(\mathrm{k}-1) !+\ldots+(\mathrm{i}-1) \\
{\left[\mathrm{a}_{\mathrm{i}-1}-(\mathrm{i}-2) \mathrm{a}_{\mathrm{i}-2}+\ldots+(-1)^{\mathrm{i}-3}(\mathrm{i}-2) \mathrm{a}_{2}+(-1)^{\mathrm{i}-2} \mathrm{a}_{1}\right]+} \\
{\left[\mathrm{a}_{\mathrm{i}}-(\mathrm{i}-1) \mathrm{a}_{\mathrm{i}-1}+\ldots+(-1)^{\mathrm{i}-2}(\mathrm{i}-1) \mathrm{a}_{2}+(-1)^{\mathrm{i}-\mathrm{a}} \mathrm{a}_{1}\right]}
\end{gathered}
$$

Corresponding author: Nick Huo Han Huang, a M.S. Math Enthusiast, research field: Number Theory. E-mail: a_Qs_dad@yahoo.com.

$$
\begin{aligned}
& =\left(\begin{array}{c}
i-1 \\
0
\end{array}\right) \mathrm{a}_{1}+\left(\begin{array}{c}
i-1 \\
1
\end{array}\right)\left(\mathrm{a}_{2}-\mathrm{a}_{1}\right)+\left(\begin{array}{c}
i-1 \\
2
\end{array}\right)\left(\mathrm{a}_{3}-2 \mathrm{a}_{2}+\mathrm{a}_{1}\right)+\left(\begin{array}{c}
i-1 \\
3
\end{array}\right) \\
& \left(\mathrm{a}_{4}-3 \mathrm{a}_{3}+3 \mathrm{a}_{2}-\mathrm{a}_{1}\right)+\ldots+\left(\begin{array}{c}
i-1 \\
k-1
\end{array}\right)\left[\mathrm{a}_{\mathrm{k}}-(\mathrm{k}-1) \mathrm{a}_{\mathrm{k}-1}+\ldots+(-1)^{\mathrm{k}-\mathrm{j}}\right. \\
& \left.\left(\begin{array}{c}
k-1 \\
k-j
\end{array}\right) \mathrm{a}_{\mathrm{j}}+\ldots+(-1)^{\mathrm{k}-2}(\mathrm{k}-1) \mathrm{a}_{2}+(-1)^{\mathrm{k}-1} \mathrm{a}_{1}\right]+\ldots+\left(\begin{array}{c}
i-1 \\
i-2
\end{array}\right)\left[\mathrm{a}_{\mathrm{i}-1}-(\mathrm{i}\right. \\
& \left.-2) \mathrm{a}_{\mathrm{i}-2}+\ldots+(-1)^{\mathrm{i}-3}(\mathrm{i}-2) \mathrm{a}_{2}+(-1)^{\mathrm{i}-2} \mathrm{a}_{1}\right]+\left(\begin{array}{c}
i-1 \\
i-1
\end{array}\right)\left[\mathrm{a}_{\mathrm{i}}-(\mathrm{i}-1) \mathrm{a}_{\mathrm{i}-1}+\right. \\
& \left.\ldots+(-1)^{\mathrm{i}-2}(\mathrm{i}-1) \mathrm{a}_{2}+(-1)^{\mathrm{i}-1} \mathrm{a}_{1}\right] \\
& =\sum_{k=1}^{i}\left(\begin{array}{c}
i-1 \\
k-1
\end{array}\right) \sum_{j=1}^{k}(-1)^{k-j}\left(\begin{array}{c}
k-1 \\
j-1
\end{array}\right) a_{j} \quad(01)^{<1>} \\
& =\mathrm{a}_{1} \sum_{k=1}^{i}(-1)^{\mathrm{k}-1}\left(\begin{array}{c}
\mathrm{i}-1 \\
\mathrm{k}-1
\end{array}\right)+ \\
& \mathrm{a}_{2} \sum_{k=2}^{i}(-1)^{\mathrm{k}-2}\left(\begin{array}{c}
\mathrm{i}-1 \\
\mathrm{k}-1
\end{array}\right)\left(\begin{array}{l}
\mathrm{k}-1 \\
\mathrm{k}-2
\end{array}\right)+ \\
& \mathrm{a}_{3} \sum_{k=3}^{i}(-1)^{\mathrm{k}-3}\left(\begin{array}{c}
\mathrm{i}-1 \\
\mathrm{k}-1
\end{array}\right)\left(\begin{array}{l}
\mathrm{k}-1 \\
\mathrm{k}-3
\end{array}\right)+\ldots+ \\
& \mathrm{a}_{\mathrm{j}} \sum_{k=j}^{i}(-1)^{\mathrm{k}-\mathrm{j}}\left(\begin{array}{l}
\mathrm{i}-1 \\
\mathrm{k}-1
\end{array}\right)\left(\begin{array}{l}
\mathrm{k}-1 \\
\mathrm{k}-\mathrm{j}
\end{array}\right)+\ldots+ \\
& a_{i-2}\left[\left(\begin{array}{c}
i-1 \\
i-3
\end{array}\right)\left(\begin{array}{c}
i-3 \\
0
\end{array}\right)-\left(\begin{array}{c}
i-1 \\
i-2
\end{array}\right)\left(\begin{array}{c}
i-2 \\
1
\end{array}\right)+\left(\begin{array}{c}
i-1 \\
i-1
\end{array}\right)\left(\begin{array}{c}
\mathrm{i}-1 \\
2
\end{array}\right)\right]+ \\
& \mathrm{a}_{\mathrm{i}-1}\left[\left(\begin{array}{c}
\mathrm{i}-1 \\
\mathrm{i}-2
\end{array}\right)\left(\begin{array}{c}
\mathrm{i}-2 \\
0
\end{array}\right)-\left(\begin{array}{c}
\mathrm{i}-1 \\
\mathrm{i}-1
\end{array}\right)\left(\begin{array}{c}
\mathrm{i}-1 \\
1
\end{array}\right)\right]+\mathrm{a}_{\mathrm{i}}\left(\begin{array}{c}
\mathrm{i}-1 \\
\mathrm{i}-1
\end{array}\right)\left(\begin{array}{c}
\mathrm{i}-1 \\
0
\end{array}\right) \\
& =\sum_{j=1}^{i} \mathrm{a}_{\mathrm{j}} \sum_{k=j}^{i}(-1)^{\mathrm{k}-\mathrm{j}}\left(\begin{array}{c}
i-1 \\
k-1
\end{array}\right)\left(\begin{array}{l}
\mathrm{k}-1 \\
\mathrm{k}-\mathrm{j}
\end{array}\right)
\end{aligned}
$$

With the above (01) and (02) formulas and $\mathrm{i}=1$ to $\mathrm{n}$, 
then $a_{i}$ of the sequence can be iterated over by a(i), which is a polynomial of i, i.e. $a_{i}$ is a discrete function of $i$, and the highest exponent is $i-1$ for each related term. So the $a_{i}$ is successfully corresponded to $i, i=1$ to $\mathrm{n}$, and is nothing to do with how big or small the $\mathrm{n}$ is; and a linear combination of its predecessor terms and itself, and nothing to do with those terms behind. And reversely, those successor terms ahead can be ignored to build $a_{i}$ when a count-down order of $i$ is applied because $\left(\begin{array}{c}i-1 \\ k-1\end{array}\right)=\left(\begin{array}{c}i-1 \\ i-k+1\end{array}\right)$, and neither formulas depend on the giving $n$, which is the order of the number sequence, or $\mathrm{n}-1$ the dimension of the Number Space. And $\mathrm{a}_{\mathrm{i}}$ 's form an infinite series when $\mathrm{i}=1$ to $\infty$.

\section{Infinite Arithmetic Progression}

In the formula (01), the coefficients of binomial ${ }^{<>}$ $(-1+1)^{\mathrm{k}-1}, \mathrm{k}=1$ to $\mathrm{i}$, and $(1+1)^{\mathrm{i}-1}$ play significant roles, but in the formula (02), there are of $( \pm 1+1)^{\mathrm{i}-1}$ and $( \pm 1+1)^{\mathrm{j}-1}, \mathrm{j}=1$ to $\mathrm{i}$. And the formula (02) means,

$$
\sum_{k=j}^{i}(-1)^{\mathrm{k}-\mathrm{j}}\left(\begin{array}{c}
i-1 \\
k-1
\end{array}\right)\left(\begin{array}{c}
\mathrm{k}-1 \\
\mathrm{k}-\mathrm{j}
\end{array}\right)=\mathbf{0}
$$

When $\mathrm{j}=1$ to $\mathrm{i}-1$, because

$$
\begin{gathered}
\sum_{k=j}^{j+n}(-1)^{\mathrm{k}-\mathrm{j}}\left(\begin{array}{c}
i-1 \\
k-1
\end{array}\right)\left(\begin{array}{l}
\mathrm{k}-1 \\
\mathrm{k}-\mathrm{j}
\end{array}\right)= \\
(-1)^{\mathrm{n}}\left(\begin{array}{c}
\mathrm{i}-1 \\
\mathrm{n}
\end{array}\right)\left(\begin{array}{c}
\mathrm{i}-\mathrm{n}-1 \\
\mathrm{j}-1
\end{array}\right)(\mathrm{i}-\mathrm{j}-\mathrm{n}) /(\mathrm{i}-\mathrm{j})
\end{gathered}
$$

While $n=1$ to $i-j-1$. And

$$
\sum_{k=1}^{j}(-1)^{\mathrm{k}-1}\left(\begin{array}{c}
i-1 \\
k-1
\end{array}\right)=(-1)^{\mathrm{j}-1}\left(\begin{array}{c}
\mathrm{i}-2 \\
\mathrm{j}-1
\end{array}\right)
$$

Which is the sum of the preceding $\mathrm{j}$ items of the coefficients of the binomial $(-1+1)^{\mathrm{i}-2}$, and $\mathrm{j}=1$ to $\mathrm{i}-2$.

Assuming all $\mathrm{a}_{\mathrm{i}}$ are the same, i.e. $\mathrm{n}=1$, a 0 -dimension number space, e.g. $\mathrm{a}_{\mathrm{i}}=1, \mathrm{i}=1$ to $\infty$, then,

$$
\sum_{k=1}^{i}\left(\begin{array}{c}
i-1 \\
k-1
\end{array}\right) \sum_{j=1}^{k}(-1)^{\mathrm{k}-\mathrm{j}}\left(\begin{array}{c}
\mathrm{k}-1 \\
\mathrm{j}-1
\end{array}\right)=1
$$

It means,

$$
\sum_{k=1}^{i}\left(\begin{array}{c}
i-1 \\
k-1
\end{array}\right)(-1+1)^{\mathrm{k}-1}=1
$$

i.e. $0^{0}=1$, an implication of that the order of the sequence is 1 and the dimension of the number space is 0 , and $\mathrm{a}^{(1)}=0$, the first and above order difference of the number sequence are 0 .

And if $\mathrm{a}_{\mathrm{i}}$ corresponds to natural number $\mathrm{i}$, then it is a 2-order number sequence because $\mathrm{a}^{(1)}=1$ and $\mathrm{a}^{(2)}=0$, and is also called a 2-order arithmetic progression, series with the same nonzero difference between adjacent terms.

$$
\sum_{k=1}^{\mathrm{i}}\left(\begin{array}{l}
i-1 \\
\mathrm{k}-1
\end{array}\right)(-1)^{\mathrm{k}-1}(\mathrm{C}+k-1)=0 \text {, C is a constant }
$$
and $i$ can be any natural numbers greater than 1 , while $\sum_{k=1}^{i}\left(\begin{array}{l}i-1 \\ \mathrm{k}-1\end{array}\right)(-1)^{\mathrm{k}-1}(\mathrm{C}+k-1)=\mathrm{C}$ when $\mathrm{i}=1$, because the natural numbers system is just a 1-dimension number space.

And for an m-order number sequence, the below equation holds.

$$
\sum_{k=1}^{i}\left(\begin{array}{l}
i-1 \\
\mathrm{k}-1
\end{array}\right)(-1)^{\mathrm{k}-1} \mathrm{p}(k, m)=0, \mathrm{i}>\mathrm{m}+1
$$

$\mathrm{p}(\mathrm{k}, \mathrm{m})$ is $\mathrm{m}^{\text {th }}$ polynomial of $\mathrm{i}$, because $\mathrm{p}^{(\mathrm{m}+1)}(\mathrm{k}$, $\mathrm{m})=0$.

Natural Numbers System is there to be discovered and could be recognized with boundless implications and inner beauties.

\section{Acknowledgment}

I thank Jack Chao Hua Huang and his Anka Inflatable Company, who generously facilitated my RMB to USD payment process for the service fee the paper.

\section{Notes}

$<1>$ It is a quasi-Taylor expansion, a Maclaurin's series, $\sum_{k=1}^{i}\left(\begin{array}{l}i-1 \\ k-1\end{array}\right) a^{(k)}$, $a^{(k)}$ is a k-order difference of a(i), i.e. $a^{(k-1)}=\sum_{j=1}^{k}(-1)^{k-j}\left(\begin{array}{c}k-1 \\ j-1\end{array}\right) a_{j}$

$<2>$ The Binomial Coefficients are generated by a typical birth process of two numbers, i.e. successor is a combination of two predecessors.

Firstly, giving the below series:

$$
a_{1}, a_{2}, a_{3}, a_{4}, a_{5}, a_{6}, a_{7}, a_{8}, \ldots,
$$

then we have a higher order one: 


$$
\begin{gathered}
b_{1}\left(a_{1}+a_{2}\right), b_{2}\left(a_{2}+a_{3}\right), b_{3}\left(a_{3}+a_{4}\right), b_{4}\left(a_{4}+a_{5}\right), \\
b_{5}\left(a_{5}+a_{6}\right), b_{6}\left(a_{6}+a_{7}\right), b_{7}\left(a_{7}+a_{8}\right), \ldots,
\end{gathered}
$$

and again:

$$
\begin{gathered}
c_{1}\left(b_{1}+b_{2}\right), c_{2}\left(b_{2}+b_{3}\right), c_{3}\left(b_{3}+b_{4}\right), \\
c_{4}\left(b_{4}+b_{5}\right), c_{5}\left(b_{5}+b_{6}\right), c_{6}\left(b_{6}+b_{7}\right), \ldots,
\end{gathered}
$$

and

$$
\begin{gathered}
d_{1}\left(c_{1}+c_{2}\right), d_{2}\left(c_{2}+c_{3}\right), d_{3}\left(c_{3}+c_{4}\right), d_{4}\left(c_{4}+c_{5}\right), \\
d_{5}\left(c_{5}+c_{6}\right), \ldots,
\end{gathered}
$$

and

$e_{1}\left(d_{1}+d_{2}\right), e_{2}\left(d_{2}+d_{3}\right), e_{3}\left(d_{3}+d_{4}\right), e_{4}\left(d_{4}+d_{5}\right), \ldots$ and

Then we have the binomial coefficients formulas because

$$
\begin{gathered}
c_{1}=a_{1}+2 a_{2}+a_{3}, c_{2}=a_{2}+2 a_{3}+a_{4}, c_{3}=a_{3}+2 a_{4}+a_{5}, \\
c_{4}=a_{4}+2 a_{5}+a_{6}, c_{5}=a_{5}+2 a_{6}+a_{7}, c_{6}=a_{6}+2 a_{7}+a_{8}, \ldots \\
d_{1}=a_{1}+3 a_{2}+3 a_{3}+a_{4}, d_{2}=a_{2}+3 a_{3}+3 a_{4}+a_{5}, \\
d_{3}=a_{3}+3 a_{4}+3 a_{5}+a_{6}, d_{4}=a_{4}+3 a_{5}+3 a_{6}+a_{7}, \\
d_{5}=a_{5}+3 a_{6}+3 a_{7}+a_{8}, \ldots \\
e_{1}=a_{1}+4 a_{2}+6 a_{3}+4 a_{4}+a_{5}, e_{2}=a_{2}+4 a_{3}+6 a_{4}+4 a_{5}+a_{6},
\end{gathered}
$$

$$
e_{3}=a_{3}+4 a_{4}+6 a_{5}+4 a_{6}+a_{7}, e_{4}=a_{4}+4 a_{5}+6 a_{6}+4 a_{7}+a_{8}, \ldots
$$

Two adjacent items make next one is binomial, and three's trinomial, and four's quadrinomial.... i.e. the coefficients of n-item make n's power, just like binomial's making 2's powers'.

2, 3, and 4's powers can be easily constructed by addition processes of planar regular number matrices [1] but not 5 and above.

It is the difference if the terms of the higher order sequence are formed as below:

$b_{1}\left(-a_{1}+a_{2}\right), b_{2}\left(-a_{2}+a_{3}\right), b_{3}\left(-a_{3}+a_{4}\right), b_{4}\left(-a_{4}+a_{5}\right), b_{5}\left(-a_{5}+a_{6}\right)$, $b_{6}\left(-a_{6}+a_{7}\right), b_{7}\left(-a_{7}+a_{8}\right), \ldots$, and so on $c_{i}$, di, and $e_{i}$, then we have differences of any order of the number sequence $\mathrm{a}_{\mathrm{i}}$. And the trinomial, quadrinomial, or even polynomial can be done the same.

\section{References}

[1] Nick Huang Huo Han, Constructions with Numbers, Journal of Mathematics and System Science, 6(5) 2016, 166-167. 